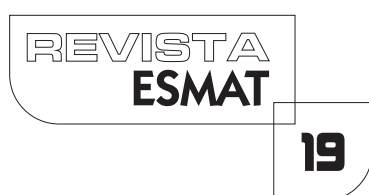

\title{
BREVES CONSIDERAÇÕES SOBRE A LITIGÂNCIA DE INTERESSE PÚBLICO: CARACTERIZAÇÃO, DIREITOS TUTELADOS E EXECUTABILIDADE DAS DECISÕES JUDICIAIS PROFERIDAS
}

BRIEF CONSIDERATIONS ON THE LITIGATION OF PUBLIC INTEREST: CHARACTERIZATION, RIGHTS GUARANTEED AND EXECUTABILITY OF PROFESSIONAL

Henrique Bedetti Bastos Mayrink

Mestrando em Direito nas Relações Econômicas e Sociais, pelas Faculdades Milton Campos. Bacharel em Direito, pela mesma instituição de ensino (20 I 3). É coordenador adjunto do Núcleo de Estudos em Solução de Conflitos das Faculdades Milton Campos. Advogado sócio do MMG Advocacia.

\section{RESUMO}

Este trabalho aborda a litigância de interesse público como instrumento de efetivação de políticas públicas indevidamente implementadas pelo poder público. Aborda-se, em primeiro lugar, o delineamento doutrinário do conceito jurídico indeterminado de interesse público. Em segundo lugar, passa-se à análise dos direitos e interesses tutelados pela litigância em apreciação, quais sejam: difusos, coletivos e individuais homogêneos. Por fim, mas não menos importante, trata-se da natureza jurídica do provimento judicial proferido e a sua respectiva executabilidade, considerando-se sempre as peculiaridades dos litígios e a dificílima questão de satisfazer plenamente os direitos dos litigantes.

PALAVRAS-CHAVE: Litigância de Interesse Público; Decisões Judiciais.

\begin{abstract}
This work deals with public interest litigation as an instrument for the implementation of public policies improperly implemented by public authorities. The first is the doctrinal delineation of the indeterminate juridical concept of public interest. Secondly, we analyze the rights and interests protected by the litigation under consideration, namely: diffuse, collective and individual homogeneous. Last but not least, this concerns the legal nature of the judicial procedure and its enforceability, always taking into account the peculiarities of litigation and the very difficult question of fully satisfying the rights of litigants.
\end{abstract}

KEYWORDS: Public Interest Litigation; Judicial Decisions. 


\section{INTRODUÇÃO}

Direito Processual Civil foi, doutrinariamente, estruturado para a solução de litígios típicos, isto é, litígios nos quais se evidenciam polos (ativo e passivo) da relação jurídica processual.

Por um lado, o polo ativo da demanda, composto por uma ou mais partes, apresenta, na peça inaugural, pretensão fundamentada fática e juridicamente, a fim de satisfazer o direito material perseguido. Por outro lado, o polo passivo, igualmente composto por uma ou mais partes, apresenta defesa (contestação e/ou reconvenção) a fim de afastar a pretensão. Ao final, profere o órgão julgador decisão judicial, solucionando o conflito.

A estrutura processual para a solução de litígios típicos satisfaz, destacadamente, litígios privados - litígios nos quais predomina a autonomia privada dos particulares em contraponto à intervenção estatal na gestão relacional. Com isso, é certo afirmar que a estrutura processual em análise soluciona a maior parte dos conflitos apresentados ao poder judiciário.

Entretanto, parcela dos litígios que tratam de questões atinentes ao direito público ou que tratam de situações de extrema complexidade reguladas pelo direito privado não é satisfeita pela estrutura processual. Isso porque, quando essa parcela de litígios é apresentada ao poder judiciário para apreciação e julgamento, este fica limitado pelo princípio da congruência ou adstrição (CPC/20 I 5, arts. I4I e 492) '̀̀ escolha entre as opções apresentadas pelas partes. Não obstante, nem sempre a melhor opção para a satisfação do direito material a ser seguida é aquela apresentada pelos polos da relação jurídica processual (ARENHART, 20 I3, p. 78).

A título de exemplificação, imagine que sociedade empresária ajuíze ação judicial de reintegração de posse em desfavor de movimento social que ocupe efetivamente o terreno objeto da demanda.

Pelos limites da lide, está claro que o julgador deverá decidir entre reintegrar, ou não, a posse. Assim, caso entenda pela reintegração, as famílias ocupantes deverão se deslocar para outra área da cidade, acarretando impactos setoriais diversos. Nessa hipótese vergastada, tem-se que a decisão proferida afetará não apenas as partes da demanda judicial, como também o poder público, porque a demanda trata de direito de moradia, direito este constitucionalmente garantido, e obrigação do poder público, que deverá providenciar moradia para todas as famílias e garantir o mínimo para a subsistência e desenvolvimento daquelas pessoas.

'Art. | 4 I. O juiz decidirá o mérito nos limites propostos pelas partes, sendo-lhe vedado conhecer de questões não suscitadas a cujo respeito a lei exige iniciativa da parte.

Art. 492. É vedado ao juiz proferir decisão de natureza diversa da pedida, bem como condenar a parte em quantidade superior ou em objeto diverso do que lhe foi demandado.

Parágrafo único. A decisão deve ser certa, ainda que resolva relação jurídica condicional. 
Outro exemplo rotineiramente averiguado é aquele em que determinado cidadão ajuíza ação para obtenção de tratamento médico-hospitalar em caráter urgente. Ao conceder o tratamento, age com prudência o órgão judicial que propicia um mal menor à instituição hospitalar (custeio de tratamento) em detrimento de um bem maior ao pleiteante (manutenção da vida). Contudo, ao conceder o direito material, em tutela provisória de urgência, o poder judiciário desconsidera alguns fatores importantíssimos, como: a listagem de pessoas que aguardam o mesmo tratamento e que, por vezes, estão em situação igual ou pior àquele que teve seu direito judicialmente concedido; a manutenção da atividade médico-hospitalar; a previsão orçamentária destinada à saúde; a alocação de recursos de um setor governamental para outro a fim de atender à decisão judicial (por exemplo, recurso alocado da educação para a saúde).

Nos exemplos destacados, observa-se que a estrutura processual colocada à disposição do poder judiciário é insuficiente para a efetivação plena das decisões judiciais. Essas demandas, denominadas de litigância de interesse público, apresentam em comum o caráter coletivo, em que a decisão proferida afeta terceiros que não compõem a relação jurídica processual e, ainda, essas demandas são relativas a políticas públicas indevidamente implementadas pelo poder público, o que ocasiona a judicialização das questões.

Pretende-se, no estudo, analisar a litigância de interesse público; para tanto, inicialmente, tratar-se-á do interesse público, princípio geral de direito, cujo conceito é juridicamente indeterminado, na tentativa de delinear com aportes doutrinários os litígios tocantes.

Após, passar-se-á à apreciação dos diversos direitos (coletivos em sentido estrito, difusos e individuais homogêneos) que são afetados pela litigância de interesse público.

E, por fim, estudar-se-ão as decisões proferidas em tais casos. Decisões que, devido à complexidade de conteúdo, apresentam extrema dificuldade para serem executadas pelo poder judiciário. Nesse ponto, averigua-se o tratamento dispensado pela doutrina ao processo coletivo e a tutela por ele ofertada ao jurisdicionado, na tentativa de satisfazer demandas peculiares que exigem estrutura processual diferenciada.

Ademais, é de destacar que não se pretende no estudo apresentar possíveis soluções generalistas às questões, até mesmo porque estar-se-ia diante de soluções inexequíveis. Cada caso apresenta determinada particularidade e como tal deve ser tratado, carecendo de tutela específica.

\section{DELINEAMENTO DE INTERESSE PÚBLICO}

É preciso, inicialmente, antes de adentrar as peculiaridades referentes à litigância em exame, adentrar a específica questão do interesse público.

Interesse público é princípio atinente ao Direito Administrativo.

Certo é que não há previsão explícita na Constituição da República no que tange à norma em apreciação. Aqui, é importante salientar que há doutrinadores que perfilham 
ser inexistente tal princípio ante o interesse privado. Nesse sentido, a lição de CARVALHO FILHO(20I5, p. 32 e 33):

\begin{abstract}
Algumas vozes se têm levantado atualmente contra a existência do princípio em foco, argumentando-se no sentido da primazia de interesse privados com suporte em direitos fundamentais quando ocorrem determinadas situações específicas. Não lhes assiste razão, nessa visão pretensamente modernista. Se é evidente que o sistema jurídico assegura aos particulares garantias contra o Estado em certos tipos de relação jurídica, é mais evidente ainda que, como regra, deva respeitar-se o interesse coletivo quando em confronto com o interesse particular. A existência de direitos fundamentais não exclui a densidade do princípio. Este é, na verdade, o corolário natural do regime democrático, calcado, como por todos sabido, na preponderância das maiorias. A "desconstrução" do princípio espelha uma visão destorcida e coloca em risco a própria democracia; o princípio, isto sim, suscita "reconstrução", vale dizer, adaptação à dinâmica social, como já se afirmou com absoluto acerto.
\end{abstract}

Em que pese às esparsas afirmativas de inexistência do princípio da supremacia do interesse público, a doutrina é majoritária no sentido de reconhecê-lo e de atribuí-lo à característica de conceito jurídico indeterminado. Aqui, novamente, é basilar a lição de CARVALHO FILHO (20I5, p. 35):

A despeito de não ser um conceito exato, aspecto que leva a doutrina em geral a configurá-lo como conceito jurídico indeterminado, a verdade é que, dentro da análise específica das situações administrativas, é possível ao intérprete, à luz de todos os elementos de fato, identificar o que é e o que não é interesse público dentro de suas zonas de certeza negativa e certeza positiva. Portanto cuida-se de conceito determinável.

Na doutrina estrangeira, destacável a lição de KÖBLER (1999, p.2 19), que ressalta, com propriedade, que a expressão "interesse" representa um conceito jurídico indeterminado e o seu conteúdo deve ser aferido com base no sentido e na finalidade da norma legal em questão.

Trata-se do princípio da supremacia do interesse público sobre o interesse privado de princípio geral do direito inerente a qualquer sociedade. Não se encontra, como dito, em dispositivo algum da Constituição, ainda que inúmeros acenem ou impliquem manifestações concretas deles, como, por exemplo, os princípios da função social da propriedade, da defesa do consumidor, ou do meio ambiente (art. 170, III, V e VI). Ainda, o princípio em causa é pressuposto lógico do convívio em sociedade. Para o 
Direito Administrativo, interessam apenas os aspectos de sua expressão na esfera da Administração Pública.

Assim, entende MELLO (2007, p. 603) por interesse público:

(...) o interesse coletivo primário ou simplesmente interesse público é o complexo de interesses coletivos prevalente na sociedade, ao passo que o interesse secundário é composto pelos interesses que a Administração poderia ter como qualquer de direito, interesses subjetivos, patrimoniais em sentido lato, na medida em que integram o patrimônio do sujeito. Cita como exemplo de interesse público secundário da administração o de pagar o mínimo possível a seus servidores e de aumentar ao máximo os impostos, ao passo que o interesse público primário exige, respectivamente, que os servidores sejam pagos de modo suficiente a coloca-los em melhores condições e tornar-lhes a ação mais eficaz e a não gravar os cidadãos de impostos além de certa medida.

Com isso, defronte as nuances do instituto, é possível afirmar que a litigância de interesse público reúne aspectos que sobressaltam a importância social, destacam-se: “a) a natureza e relevância dos bens jurídicos tutelados (meio ambiente, relações de consumo, saúde, educação, probidade administrativa, ordem econômica etc.); b) as dimensões ou características do ato ilícito ou da lesão; c) o elevado número de pessoas atingidas" (DIDIER e ZANETTI, 20 I6, p. 79)2.

Posto isso, para a análise do presente artigo, como permissivo para atuação do poder judiciário nos casos em que as políticas públicas articuladas restaram sem implementação, considera-se interesse público todas aquelas situações em que a atuação do ente estatal é imprescindível para consecução dos fins pretendidos mediante a tutela jurisdicional.

Ainda, importante no presente tópico, aclarar o que seja uma política pública, uma vez que é pressuposto para a intervenção judicial a sua não implementação. Afirma HOWLETT, RAMESH e PERL (20।3, p. 5):

(...) a formulação da política pública tem por característica distintiva simplesmente a proposição de meios para resolver as necessidades percebidas da sociedade. A formulação política, portanto, envolve a identificação e a determinação das possíveis soluções para os problemas políticos ou, para dizê-lo de outra

2 DIDIER JR., Fredie; ZANETI JR, Hermes. Curso de Direito Processual Civil: processo coletivo. I 0. ed. Salvador: Ed. JusPodivm, 2016. 
maneira, a exploração das várias opções ou cursos alternativos de ação disponíveis para enfrentá-los. As propostas podem surgir no próprio processo de montagem da agenda na medida em que o problema e sua respectiva solução chegam juntos à agenda do governo, ou se pode desenvolver opções após o caso após o caso em questão já ter entrado na agenda oficial. De toda forma, a extensão das opções disponíveis e consideradas neste estágio é sempre reduzida a quantas os policy-makers têm condições de acolher, antes que essas alternativas avancem para as deliberações formais dos tomadores de decisão. A definição e a ponderação dos méritos e riscos das várias opções constituem por isso a substância desse segundo estágio do processo político e certo grau de "análise política" é tipicamente um componente crítico da atividade de formulação da política ${ }^{3}$.

Sabendo-se do modo pelo qual uma política pública é formulada, parte do pressuposto para apreciação da matéria de que tal política não tenha sido, pelo menos num primeiro momento, devidamente implementada pelos seus responsáveis. E que, diante da situação de falibilidade apontada, surge a necessidade de efetivação de tais políticas por outros meios, sendo o poder judiciário a via mais recorrente pelos afetados.

Como consequências da necessária judicialização da política, podem-se apontar: a) excesso de demandas judiciais; b) demora na prestação jurisdicional; c) dificuldade de implementação das decisões judiciais, tendo em vista a complexidade das matérias envolvidas, escassez de conhecimentos técnicos e insuficiência de aparato estatal; d) panaceia do poder judiciário, entre outros.

Delineado o conceito de interesse público, parte-se para a apreciação dos direitos salvaguardados por tais litígios.

\section{INTERESSES OU DIREITOS AFETADOS PELA LITIGÂNCIA DE INTERESSE PÚBLICO: DIFUSOS, COLETIVOSE INDIVIDUAIS HOMOGÊNEOS}

A litigância de interesse público tutela os mais variados direitos existentes. De direitos individuais a direitos coletivos lato sensu.

Já afirmamos anteriormente que a estrutura polarizada do Direito Processual Civil Brasileiro é insuficiente para a integral guarida dos direitos existentes. Não obstante, em tempos modernos, mesmo mantendo a polarização das relações jurídicas processuais inalteradas, o legislador pátrio concebeu instrumentos processuais diversos para a tutela de direitos coletivos. Esses litígios, pela natureza de seus direitos, diferem dos demais,

\footnotetext{
${ }^{3}$ HOWLETT, Michael; RAMESH, M; PERL, Anthony. Política Pública: seus ciclos e subsistemas: uma abordagem integral. Rio de Janeiro: Elsevier, 20 13.p. 5.
} 
merecendo mais atenção. Nesse diapasão, a lição de MOREIRA(| 99| , p. | 88):

(...) do ponto de vista objetivo, esses litígios a que eu chamei de essencialmente coletivos distinguem-se porque o seu objetivo é indivisível. Não se trata de uma justaposição de litígios menores, que se reúnem para formar um litígio maior. Não. O seu objeto é por natureza indivisível, como acontece, por exemplo, em matéria de proteção do meio ambiente, em matéria de defesa da flora e da fauna, em matéria de tutela dos interesses na preservação do patrimônio histórico, artístico, cultural, espiritual da sociedade; e como acontece também, numerosas vezes, no terreno da proteção do consumidor, por exemplo, quando se trata de proibir a venda, a exploração de um produto considerado perigoso ou nocivo à saúde. Não se está focalizando, nessa perspectiva, o problema isolado de cada pessoa, e sim algo que necessariamente assume a dimensão coletiva e incindível, do que resulta uma consequência muito importante, que tem, inclusive, reflexos notáveis sobre a disciplina processual a ser adotada. Em que consiste essa consequência? Consiste em que é impossível satisfazer o direito ou o interesse de um dos membros da coletividade, e viceversa: não é possível rejeitar a proteção sem que essa rejeição afete necessariamente a coletividade como tal. Se quiserem um exemplo, podemos mencionar o caso de um litígio que se forme a propósito de uma mutilação da paisagem. É impensável que a solução, seja ela qual for, aproveite a alguns e não aproveite a outros dos membros dessa coletividade. A solução será, por natureza, unitária, incindível. Ou a paisagem é protegida, é preservada, e todos os interessados são juridicamente satisfeitos, ou a paisagem não é preservada, e nenhum dos interessados na sua preservação terá satisfação jurídica.

Merece destaque também a lição de DIDIERJR(20 16, p. 34 e 35):

Os processos coletivos servem à "litigação de interesse público" (LIP); ou seja, servem às demandas judiciais que envolvam, para além dos interesses meramente individuais, aqueles referentes à preservação da harmonia à realização dos objetivos constitucionais da sociedade e da comunidade. Interesses de uma parcela da comunidade constitucionalmente reconhecida, a exemplo dos consumidores, do meio ambiente, do patrimônio artístico, histórico e cultural, saúde, educação, bem como, na defesa dos interesses dos necessitados e dos interesses minoritários nas demandas individuais clássicas (não os dos habituais polos dessas demandas, credor/devedor), 
como os das crianças e adolescentes, das pessoas institucionalizadas em hospitais e presídios, dos negros, dos índios, das mulheres, podem ser passíveis de serem veiculados como situações jurídicas coletivas merecedoras de tutela através de ações coletivas que permitam a tutela molecular de todo o grupo.

Faz-se necessário, inicialmente, definir aquilo que o legislador denominou de interesses essencialmente coletivos (lato sensu) e interesses individuais homogêneos.

Entende-se por interesses essencialmente coletivos os difusos e os coletivos. $\bigcirc$ inciso I do parágrafo único do art. 8 I do Código de Defesa do Consumidor estabeleceu a definição dos "interesses ou direitos difusos, assim entendidos, para efeitos deste Código, os transindividuais, de natureza indivisível, de que sejam titulares pessoas indeterminadas e ligadas por circunstâncias de fato. Por sua vez, o inciso II do dispositivo supracitado, estatui que os "interesses ou direitos coletivos, assim entendidos para efeitos deste Código, são os transindividuais de natureza indivisível, de que seja titular grupo, categoria ou classe de pessoas ligadas entre si ou com a parte contrária por uma relação jurídica base.

Já os direitos ou interesses individuais, para serem qualificados como homogêneos, necessitam envolver uma pluralidade de pessoas e decorrer de origem comum, situação que

(...) não significa, necessariamente, uma unidade factual e temporal. As vítimas de uma publicidade enganosa veiculada por vários órgãos de imprensa e em repetidos dias ou de um produto nocivo à saúde adquiridos por vários consumidores num largo espaço de tempo e em várias regiões têm, como causa de seus danos, fatos com homogeneidade tal que os tornam a 'origem comum' de todos eles ${ }^{4}$.

A defesa coletiva de direitos individuais atende aos ditames da economia processual, representando medida desafogadora do poder judiciário que permite e amplifica o acesso à justiça, notadamente quanto a conflitos em que o valor reduzido do benefício significa manifesto desestímulo para a formulação da demanda. Ainda, salvaguarda o princípio da igualdade da lei ao resolver uniformemente as causas repetitivas.

Diante dos inúmeros institutos e instrumentos colocados à disposição pelo legislador, afirma-se, ainda sim, que são insuficientes para a consecução dos fins perseguidos em juízo. Isso porque o órgão jurisdicional não exerce controle irrestrito sobre os demais atos executivos que extrapolem a alçada do judiciário.

${ }^{4}$ WATANABE, Kazuo. Código Brasileiro de Defesa do Consumidor: comentado pelos autores do anteprojeto. 6. ed. Rio de Janeiro: Forense, 2000. 
Segundo Marco Félix Jobim, "quando o Poder Legislativo não consegue atribuir ao povo novas leis que possam modificar esse ambiente ou quando o Poder Executivo fica inerte em seu dever de administrar, é o Poder Judiciário que deverá intervir, em ambos os casos, por meio de processos individuais ou coletivos. A esse fenômeno dá-se o nome de ativismo judicial, em contraposição à autocontenção judicial, o que, em alguns casos, pode trazer benefícios e em outros prejuízos, sendo que o ora se defende é que num ativismo judicial equilibrado a tendência do acerto é maior que a do erro". Para o autor, "o ativismo judicial utilizado de uma forma correta pode trazer benefícios extremos ao cumprimento das decisões emanadas das Cortes superiores".

Posto isso, esclarecido os direitos tutelados, passa-se ao estudo pormenorizado da executabilidade das decisões judiciais proferidas em casos de litigância de interesse público, identificando os pontos faltosos para a implementação de políticas.

\section{DECISÕES PROFERIDAS EM LITIGÂNCIA DE INTERESSE PÚBLICO E A NECESSIDADE DE EXECUTABILIDADE EFETIVA}

\section{a. NATUREZA DO PROVIMENTOJURISDICIONAL}

As decisões proferidas nos casos de litigância de interesse público, pelas peculiaridades que the são atinentes, são denominadas pela doutrina de decisões estruturais. Preleciona ARENHART (2013, 380):

A decisão estrutural (structural injunction) é, pois, aquela que busca implantar uma reforma estrutural (structural reform) em um ente, organização ou instituição, com o objetivo de concretizar um direito fundamental realizar uma determinada política pública ou resolver litígios complexos. Por isso, o processo em que ela se constrói é chamado de processo estrutural. Parte-se da premissa de que a ameaça ou a lesão que as organizações burocráticas representam para a efetividade das normas constitucionais não pode ser eliminada sem que tais organizações sejam reconstruídas.

A decisão estrutural possui conteúdo complexo.

Normalmente, prescreve uma norma jurídica de conteúdo aberto; não raro o seu preceito indica o resultado a ser alcançado - uma meta, um objetivo - assumindo, por isso, e nessa parte, a estrutura deôntica de uma norma-princípio, com o objetivo de promover um determinado estado de coisas. Mas não é só isso: é uma decisão que estrutura o modo como se deve 
alcançar esse resultado, determinando condutas que precisam ser observadas ou evitadas par que o preceito seja atendido e o resultado, alcançado - assumindo, por isso, nessa parte, a estrutura deôntica de uma norma-regra.

Sua principal característica é a acentuada intervenção judicial na atividade dos sujeitos envolvidos no processo, sejam eles particulares ou públicos. (pg. 380).

É cediço que os provimentos judiciais podem ser de natureza declaratória, constitutiva, condenatória e mandamental. Interessam para o presente estudo apenas os provimentos de natureza condenatória e mandamental.

Diz-se que o provimento condenatório contém dois momentos lógicos. O primeiro diz respeito à eficácia meramente declaratória, ao passo que o segundo refere-se à sanção executiva. É este segundo momento que distingue o provimento condenatório dos demais. Enquanto que no provimento declaratório inexiste o segundo momento lógico, no provimento constitutivo, o segundo momento refere-se à modificação jurídica desejada pelo demandante.

Os provimentos mandamentais proporcionam tutela independentemente da instauração de processo executivo. Ao comando do provimento mandamental vem imposta uma medida coercitiva a ser aplicada no caso de retinência do demandado no descumprimento da ordem. As modalidades de medidas mais conhecidas são a prisão civil e a multa periódica. Aqui se pretende permitir o fiel cumprimento da obrigação seja por meio de medidas coercitivas, seja por meio de medidas sub-rogatórias.

Certo é que o provimento jurisdicional proferido nas demandas de interesse público seja, preferencialmente, condenatório, sendo, em muitas situações, a fase instrutória suficiente para quantificar os danos. A grande questão de tais decisões é o modo pelo qual serão executadas. Esta questão será tratada a seguir.

\section{b. A EXECUTABILIDADE DAS DECISÕESJUDICIAIS}

Afirma-se, reiteradamente, que o processo, nos dias de hoje, deve ter como precípua função servir como instrumento para a consecução do direito material. Com tal afirmação, não se pretende reduzir o papel e a importância teórica, prática e técnica do Direito Processual, pois, por ser instrumento, tem qualidades, para, de modo justo, claro, sistemático, simples, econômico e rápido, oferecer soluções satisfatórias à sociedade na busca da realização dos direitos e resolução dos conflitos.

Em termos de execução e cumprimento de sentença, a Lei Federal $n^{\circ}$ | 3. I05, de 16 de março de 2015, que introduziu o Código de Processo Civil, trouxe modificações pontuais atinentes principalmente a litígios individuais.

É importante destacar também que mudanças que extrapolam os direitos ou interesses individuais também foram trazidas pelo legislador do Código de Processo Civil, de 20 I5, como, por exemplo, o incidente de resolução de demandas repetitivas, 
o incidente de assunção de competência, entre outros.

Essas louváveis mudanças introduzidas, contudo, não abarcaram os casos específicos de litigância de interesse público.

Como já afirmado, as decisões judiciais proferidas em casos de litigância de interesse público, também denominadas de decisões estruturantes, apresentam peculiaridades que as diferenciam dos provimentos jurisdicionais proferidos em casos individuais.

A decisão estruturante deverá considerar as necessidades e as contingências do caso e das partes envolvidas, adequando as imposições àquilo que seja concretamente realizável. Decisões contra o poder público, exemplificadamente, exigirão a ponderação sobre a efetiva condição da Administração Pública em cumprir o comando judicial, de que modo e em que tempo. Provimentos que imponham ônus elevados a réu particular, em geral, deverão atentar para as consequências do cumprimento, que podem levar à falência de uma sociedade empresária, à sua exclusão mercadológica ou mesmo à inviabilidade concreta do atendimento à determinação do juízo. É certo que a medida estrutural imposta deve estar em conformidade com a lesão que se almeja impedir ou reparar. Não se tolera que a decisão judicial exceda os limites do ilícito a ser guerreado, sob pena de transformar o magistrado no verdadeiro gestor do órgão ou do ente responsável pela conduta aventada (ARENHART, 20 I3, p. 398).

De tal modo, consideradas as peculiaridades de uma decisão judicial proferida em casos de litigância de interesse público, há de se observar que, do mesmo modo que a construção da decisão se faz distintamente das decisões proferidas em casos individuais, o modo pelo qual tais decisões são executadas, igualmente, é diverso. Nesse sentido, a lição de DIDIERJR(20 | 6, p. 35):

A própria noção de execução muda, passando a ser exigida a execução civil desdobrada no tempo, a execução das chamadas "medidas judiciais estruturantes". Essas medidas são voltadas para a tutela específica das obrigações, muito além da pretensão obrigacional de satisfação de um crédito em dinheiro. Trata-se de medidas de performance específica (specific performance) em decisões com caráter estruturante (structural injunctions), adotando-se, na espécie, um modelo muito parecido com o modelo de execução do common law, voltado para a adequação da medida executiva às necessidades práticas de efetivação. A noção experimentalista e as medidas estruturantes permitem a um só tempo o conhecimento colaborativo do problema pelas partes e pelo juiz (colaborative learning) e uma maior responsabilização e legitimação democrática (democratic accountability), visando à efetividade da decisão judicial.

Ainda, para executar determinada medida estrutural muitas das vezes faz-se necessária uma diversidade de provimentos de modo a efetivar a política pública ali insculpida. Basilar a lição de ARENHART $(2013,380)$ : 
(...) é muito frequente no emprego de medidas estruturais a necessidade de se recorrer a provimentos em cascata, de modo que os problemas devam ser resolvidos à medida que apareçam. Assim, por exemplo, é típico das medidas estruturais a prolação de uma primeira decisão, que se limitará a fixar em linhas gerais as diretrizes para a proteção do direito a ser tutelado, criando o núcleo da posição jurisdicional sobre o problema a ele levado. Após essa primeira decisão normalmente, mais genérica, abrangente e quase "principiológica", no sentido de que terá como principal função estabelecer a "primeira impressão" sobre as necessidades da tutela jurisdicional - outras decisões serão exigidas, para a solução de problemas e questões pontuais, surgidas na implementação da "decisão-núcleo", ou para a especificação de alguma prática devida. Possivelmente, isso se sucederá em uma ampla cadeia de decisões, que implicarão avanços e retrocessos no âmbito de proteção inicialmente afirmado, de forma a adequar, da melhor forma viável, a tutela judicial àquilo que seja efetivamente possível de se lograr no caso concreto. Não raras vezes, esses provimentos implicarão técnicas semelhantes à negociação e à mediação.

provimento jurisdicional proferido em casos de litigância de interesse público pode delegar a execução ou a fiscalização do conteúdo decisório a órgãos diversos, estabelecer etapas para o cumprimento, indicar sujeitos diversos ao feito de esboçar plano de cumprimento, adotar outras medidas exigidas concretamente. Enfim, deve haver margem ampla para a gestão da decisão judicial. Pode-se ditar à Administração Pública qual o objetivo a ser atingido, reservando-lhe a escolha dos meios e preservando sua discricionariedade, ou se pode estabelecer desde logo um cronograma de atividades a serem seguidas. Pode-se, também, escalonar medidas a serem adotadas no tempo, com prestação de contas periódicas. Isso tudo, de modo ao desenvolvimento e à satisfação da prestação jurisdicional (ARENHART, 20 I3, p. 380).

\section{CONCLUSÃO}

Por todo o exposto, tem-se que o poder judiciário é democraticamente legitimado a intervir em casos de implementação indevida de políticas públicas a fim de concretizálas.

Em que pese à legitimação atribuída ao órgão judiciário, o modo pelo qual os provimentos judiciais são executados poderá acarretar a ineficácia da política, motivo pelo qual se devem observar diversas questões de índole material e processual.

Para que as políticas sejam executadas adequadamente, faz-se necessária a fragmentação das situações de extrema complexidade (fática ou jurídica). Isso possibilita a efetivação das medidas estruturais e o alcance dos objetivos traçados pelas políticas públicas. 


\section{REFERÊNCIAS}

ARENHART, Sérgio Cruz. Decisões Estruturais no Direito Processual Brasileiro. RePro, São Paulo: RT, v. 225, out./nov. 2013.

CARVALHO FILHO, José dos Santos. Manual de Direito Administrativo. 25. ed. rev. ampl. e atual. São Paulo: Atlas, 2012.

DIDIER JR., Fredie; ZANETI JR, Hermes. Curso de Direito Processual Civil: processo coletivo. 10. ed. Salvador: Ed. JusPodivm, 2016.

HOWLETT, Michael; RAMESH, M; PERL, Anthony. Política Pública: seus ciclos e subsistemas: uma abordagem integral. Rio de Janeiro: Elsevier, 2013.

JOBIM, Marco Félix. Medidas estruturantes: da Suprema Corte Estadunidense ao Supremo Tribunal Federal. Porto Alegre: Livraria do Advogado, 20 I 3. p. 104.

LUCON, Paulo Henrique dos Santos (coord.). Tutela Coletiva: 20 anos da Lei de Ação Civil Pública e do Fundo de Defesa de Direitos Difusos, 15 anos do CDC. São Paulo: Atlas, 2006.

MARINONI, Luiz Guilherme. Tutela inibitória: individual e coletiva. 3. ed. São Paulo: Revista dos Tribunais, 2003.

MENDES, Aluisio Gonçalves de Castro. Ações coletivas e meios de resolução de conflitos no direito comparado e nacional. 4. ed. rev. ampl. e atual. São Paulo: Revista dos Tribunais, 2014.

MOREIRA, José Carlos Barbosa. Ações Coletivas na Constituição Federal de 1988. RePro. v. 6I. São Paulo: Revista dos Tribunais, jan./mar. I991.

NEVES, Daniel Amorim Assumpção. Manual de processo coletivo. Rio de Janeiro: Forense, 2012.

WATANABE, Kazuo. Código Brasileiro de Defesa do Consumidor: comentado pelos autores do anteprojeto. 6. ed. Rio de Janeiro: Forense, 2000.

ZAVARSCKI, Teori Albino. Processo Coletivo: tutela de direitos coletivos e tutela coletiva de direitos. 6. ed. rev. e. ampl. São Paulo: Revista dos Tribunais, 20 I 4.

Recebido em: 23/01/2018

Aprovado em: 24/01/2020 
